\title{
Impedance Sensing for Monitoring Neuronal Coverage and Comparison With Microscopy
}

\author{
R. W. F. Wiertz, W. L. C. Rutten*, Member, IEEE, and E. Marani
}

\begin{abstract}
We investigated the applicability of electric impedance sensing (IS) to monitor the coverage of adhered dissociated neuronal cells on glass substrates with embedded electrodes. IS is a sensitive method for the quantification of changes in cell morphology and cell mobility, making it suitable to study aggregation kinetics. Various sizes of electrodes were compared for the real-time recording of the impedance of adhering cells, at eight frequencies (range: $5 \mathrm{~Hz}-20 \mathrm{kHz}$ ). The real part of the impedance showed to be most sensitive at frequencies of 10 and $20 \mathrm{kHz}$ for the two largest electrodes $\left(7850\right.$ and $\left.125600 \mu \mathrm{m}^{2}\right)$. Compared to simultaneous microscopic evaluation of cell coverage and cell spreading, IS shows more detail.
\end{abstract}

Index Terms-Aggregation, electric impedance sensing (IS), neuronal cell coverage, neuronal cultures.

\section{INTRODUCTION}

$\mathbf{T}$ O ASSAY the process of attachment of cells to artificial surfaces several techniques have been used. Most quantitative studies on adhesion involve employing forces like centrifugal acceleration and laminar shear flow [1], [2]. These techniques are laborious and noncontinuous. Another technique is microscopy, often in combination with immunocytochemical staining, direct cell counting, or time lapse cinematography [3]-[5]. Electric impedance sensing (IS) is a continuous method, providing quantitative data on several cultures simultaneously with a relatively high time resolution [6]-[10].

In IS cells are cultured on microelectrodes and submitted to an ac current. Current can flow through the cell membranes and via the openings between tightly adhered, but not totally confluent cells.

The impedance measured depends on a number of variables, such as adhesion tightness, cell type, surface area of the electrode, frequency, and confluency of cells. Depending on the application an optimal set of variables has to be chosen. In the methods section this will be further elaborated on.

Assuming that cells are firmly adhered (sealed) to the substrates, and stay adhered when openings between the cells grow

Manuscript received February 12, 2010; revised May 18, 2010; accepted June 18, 2010. Date of publication June 28, 2010; date of current version September 15, 2010. Asterisk indicates corresponding author.

R. W. F. Wiertz and E. Marani are with the Department of Electrical Engineering, University of Twente, Enschede 7500 AE, The Netherlands (e-mail: remywiertz@hotmail.com; e.marani@utwente.nl).

*W. L. C. Rutten is with the Department of Electrical Engineering, University of Twente, Enschede 7500 AE, The Netherlands (e-mail: w.1.c.rutten@utwente.nl).

Color versions of one or more of the figures in this paper are available online at http://ieeexplore.ieee.org.

Digital Object Identifier 10.1109/TBME.2010.2055052 or shrink, changes in cell confluency will affect mainly the intercellular resistance (spreading resistance, or constriction resistance). Due to the low resistivity of the culturing fluid, compared to the membrane impedance and sealing resistance, even slight changes in the openings have very large effects on the impedance, as given in [9] and [10].

IS has proven valuable for study of the cell or tissue interface and the monitoring of changes in mammalian cell-culture morphology [7]-[10]. Several electric models of electrodefluid-cell/tissue have been developed [7]-[10]. Changes in cell shape caused by various biochemicals like $\alpha$-thrombin [11] and prostaglandin E [12] have been monitored as well as changes caused by cytotoxic agents [13], virus infections [14], or even very small changes in morphology caused by periodic injection of $\mathrm{CO}_{2}$ in cell culture incubators [15].

So far, no research has been reported in which IS was applied on dissociated primary neuronal cell cultures. IS has been reported in studies involving mammalian cell types with tight intracellular clefts, whereas neurons have far less-defined cellcell contacts and do not divide. In a study by Bieberich and Guiseppi-Elie [16], the neuronal differentiated cancer cell line PC-12 showed an almost 3\% higher impedance compared to nondifferentiated PC-12 cells. Another study demonstrated a significant increase in impedance during the attachment of neuroblastoma cells on an electrode [17].

In this study, neuronal cultures were investigated during normal development in two ways: IS and microscopy. Directly after plating, the neurons start to spread and make contact with surrounding cells, leading to a rather confluent monolayer of neurons. Both methods were compared to test whether IS shows more details than standard microscopy.

\section{Materials AND MethodS}

\section{A. Planar Electrodes}

Fig. 1 shows an overview of the four electrode sizes used for IS. Dimensions of the electrodes are 78, 1962, 7850, and $125600 \mu \mathrm{m}^{2}$. Electrodes were patterned on $1 \mathrm{~cm}^{2}$ glass plates. Each glass plate contained 19 electrodes of one size. Glass was used as a substrate in order to have transparency between electrodes. Gold electrode structures were created by photolithography and reactive ion etching. An insulation sandwiched layer combination of $\mathrm{SiO}_{2}-\mathrm{Si}_{3} \mathrm{~N}_{4}-\mathrm{SiO}_{2}$ (144-396-144 nm thick) was deposited by plasma-enhanced chemical vapor deposition. The insulation was etched away above the electrodes. After fabrication, the electrode plates were cleaned ultrasonically in an acetone bath. 

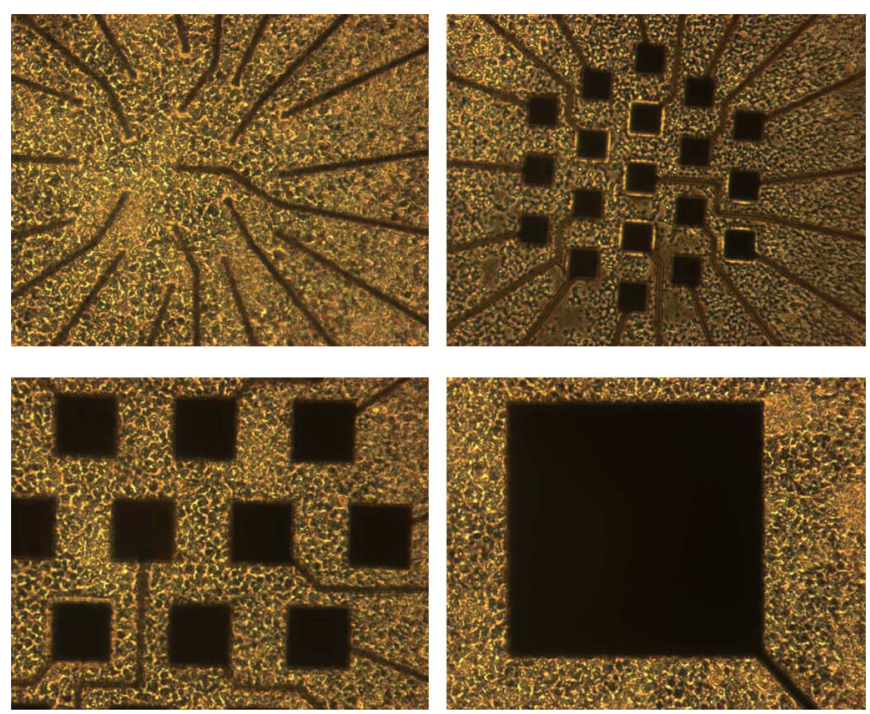

Fig. 1. Cell-covered gold electrodes $\left(78,1962,7850\right.$, and $\left.125600 \mu \mathrm{m}^{2}\right)$.

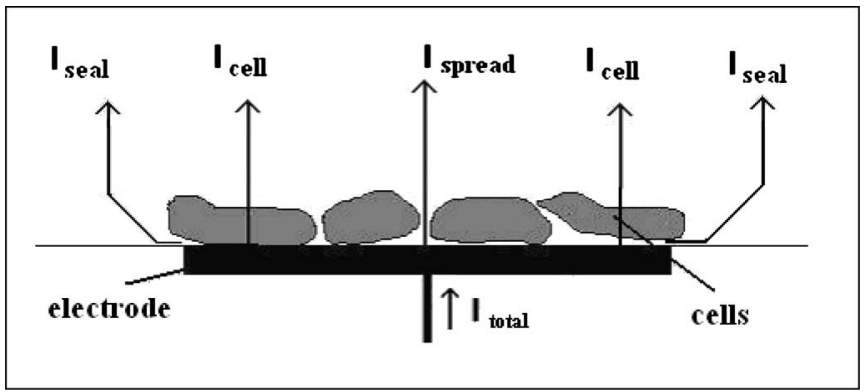

Fig. 2. Schematic view of an electrode covered with neurons. The total current $I_{\text {total }}$ splits up into three pathways. Current $I_{\text {spread }}$ finding its way "easily" through the small spaces between the cells, $I_{\text {seal }}$, the leakage current through the gaps between the substrate and the cells, and $I_{\text {cell }}$, the current through the cells.

Neurons were plated and cultured on and around the electrode areas (see Fig. 1). The electrode glass plates were precoated with $50 \mu \mathrm{g} / \mathrm{mL}$ polyethyleneimine (PEI; Fluka, Buchs, Switzerland). For the positioning of a neuronal culture, a glass ring was placed on the substrate during cell plating.

\section{B. Impedance Model}

Fig. 2 shows a schematic view of an electrode covered by neurons. The impedance spectrum of this system can be analyzed using an equivalent $R C$ circuit (see Fig. 3). Assuming that cells are firmly adhered to the substrates (so $R_{\text {seal }}$ is very high, typical value $5 \mathrm{M} \Omega$; see [9]), and that they stay adhered when openings between the cells grow or shrink, changes in cell confluency will affect mainly the intercellular resistance (spreading resistance $R_{\text {spread }}$ ). Due to the low resistivity of the culturing fluid, compared to the membrane impedance and $R_{\text {seal }}$, even slight changes in the openings have very large effects on the impedance, as given in [9] and [10] (for proof, see last two paragraphs of this section). Therefore, this model can be simplified

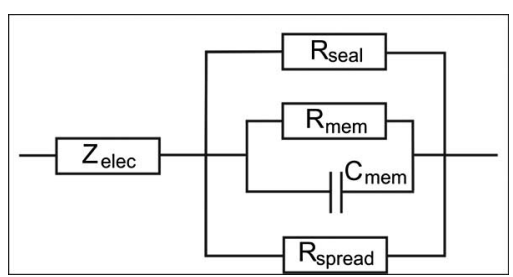

Fig. 3. Equivalent circuit. $Z_{\text {elec }}$ is the impedance of the electrode-electrolyte interface (Helmholtz double layer), $R_{\text {spread }}$ is the resistance of the intercellular open spaces and bulk fluid, and $R_{\text {seal }}$, the sealing resistance between the cells and substrate. The $R_{\mathrm{mem}} C_{\mathrm{mem}}$ part accounts for the neuronal cell membranes.

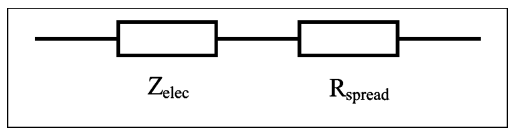

Fig. 4. Simplified equivalent circuit for an electrode.

to only $Z_{\text {elec }}$ in series with $R_{\text {spread }}$ (see Fig. 4)

$$
Z=Z_{\text {elec }}+R_{\text {spread }}=\frac{K}{(i \omega)^{m}}+R_{\text {spread }} .
$$

The first term represents the equivalent impedance of the electrode-electrolyte interface that is frequency dependent, and $K$ is a size-dependent constant [8], [19]. Power $m$ usually takes values around $0.6-0.7$, indicating the nontruly capacitive nature of the Helmholtz layer.

$R_{\text {spread }}$ can be modeled as the resistance of a fluid conductor, seen by a small source with "electrode" radius $r_{e}$,

$$
R_{\text {spread }}=\frac{\sqrt{2}}{2 \pi \sigma r_{e}} \approx \frac{1}{4.44 \sigma r_{e}}
$$

with $\sigma$ the conductivity of the culturing medium $(\sigma=1.65 \mathrm{~S} / \mathrm{m})$. Therefore, the radius $r_{e}$ is the equivalent radius of the electrode surface that is not covered by cells and depends on the cell coverage. Electrode coverage with neurons will have a main effect on the second term, as corridors will shrink/vanish when cells attach more firmly to each other, until complete confluence is reached. The neurons now impede the passage of current, thereby increasing the total impedance.

The model approach chosen is certainly not the only possible one. A number of other, but usually more complex models exist in literature [6], [8]. However, given the purpose of analysis of development of confluency of cells, the proposed model has the strength of simplicity, with only three parameters.

We still have to check numerically whether our simplification of the electrical circuit model is justified, and so whether the ratio of $R_{\text {spread }}$ and membrane impedance is sufficiently low. For parameters $C_{m}$ and $\sigma_{m}$, we have cellular membrane capacitance $C_{m}=1 \mu \mathrm{F} / \mathrm{cm}^{2}$, membrane conductance $\sigma_{m}=0.3 \mathrm{mS} / \mathrm{cm}^{2}$ [9].

Assuming full confluency and regarding now all cells as one giant cell, with surface dimensions the same as the four electrodes areas $\left(78,1962,7850\right.$, and $\left.125600 \mu \mathrm{m}^{2}\right)$, one calculates $C_{\mathrm{m}}$ all cells $=0.39,9.81,39.25$, and $628 \mathrm{pF}$, respectively, and $R_{\mathrm{m}}$ all cells $=4270,170,42.5$, and $2.65 \mathrm{M} \Omega$, respectively. Together, they determine the membrane real impedance for 
each frequency. For example, for the $7850 \mu \mathrm{m}^{2}$ surface, and at $10 \mathrm{kHz}$, one calculates $R_{m}=42.5 \mathrm{M} \Omega$, in parallel with $Z_{C}$ (real part) $=406 \mathrm{k} \Omega$. Therefore, the membranes form together a real impedance of about $400 \mathrm{k} \Omega$, or less (when less cells present, i.e., not completely confluent). On the other hand, voids between the cells of $0.1 \%, 1 \%$, or $10 \%$ yield $R_{\text {spread }}$ values of 123,40 , and $12.2 \mathrm{k} \Omega$, respectively (2). Combining these values, one may conclude that at voids of $1 \%$ and $10 \%$ the circuit simplification is justified, as $R_{\text {spread }}$ is $10-32$ times smaller than the membrane real impedance, respectively. At $0.1 \%$ open space, the simplification is a bit too strong for the $7850 \mu \mathrm{m}^{2}, 10 \mathrm{kHz}$ combination, but will get better justified for lower frequencies or smaller electrodes. Obviously, the $R_{\text {seal }}$ value of $5 \mathrm{M} \Omega$ is large enough to be neglected, compared to the above values.

Cortical cells have a typical somatic diameter of $20 \mu \mathrm{m}$. This implies that the smallest electrode, area $78 \mu \mathrm{m}^{2}$, will be probably covered by a few cells only, or even one cell. In case of one cell, the interface lacks the spread current component. This onecell coverage case has been analyzed previously in detail by Buitenweg et al. [9], [10].

\section{Cell Culturing}

Cerebral cortical neurons from newborn rats (P2) were used for all experiments in this study. Brains were taken out after decapitation, the meninges of the cortices were removed, and the basal ganglia as well as the hippocampus was prepared free. The remaining cortices were collected in a tube with chemically defined R12 culture medium [20] and trypsin for chemical dissociation. After removal of trypsin, $150 \mu \mathrm{L}$ of soybean trypsin inhibitor and $125 \mu \mathrm{L}$ of DNAse I (20000 units, Life Technology, Carlsbad) are added. A solution of single neurons was obtained by mechanical dissociation of the cortical tissue. The neuron solution was centrifuged at $1200 \mathrm{r} / \mathrm{min}$ for $5 \mathrm{~min}$. The supernatant was removed and the pellet of neurons resuspended. Neurons were plated and cultured on the described electrodes precoated with $50 \mu \mathrm{g} / \mathrm{mL}$ PEI (Fluka). PEI is a cell-substrate adhesive enabling the neurons to adhere to the nonadhesive glass, it is routinely used in neuronal cell culturing. Cells were kept in serum-free R12 medium under standard conditions of $37^{\circ} \mathrm{C}$ and $5 \% \mathrm{CO}_{2}$ in air. A cell concentration of approximately $10^{6}$ cells $/ \mathrm{cm}^{2}$ was used in all experiments. During measurements, the neuron cultures were placed into a small incubator keeping the temperature at $37^{\circ} \mathrm{C}$. In total, five platings were done from five different rats $(N=5)$.

\section{Measurement Setup}

All impedance measurements were carried out using a programmable signal source (HP 4194A), a home-built impedance measuring circuit, and a data acquisition system in a Labview environment [9], [10]. This setup was used in combination with cell culturing chambers containing the electrodes. The cultures were kept at $37^{\circ} \mathrm{C}$ under sterile conditions during measurements on a NIKON DIAPHOT inverted microscope. Applied frequencies were 5, 10, 50, 100, 500, 1000, 10000 , and $20000 \mathrm{~Hz}$. The measurements were controlled by the same computer that recorded and saved the real and imaginary part of the impedance.
Cultures were monitored during their development, starting shortly before cell plating of the electrodes, until cultures formed compact monolayers of neurons and aggregation was just starting. In the first $12 \mathrm{~h}$, the electrodes were monitored by a set of measurements done every $3 \mathrm{~h}$ in which six impedance spectra were obtained with an interval of $2 \mathrm{~min}$ on all four devices. After $12 \mathrm{~h}$, the cultures were measured every $24 \mathrm{~h}$ ending the experiment after $144 \mathrm{~h}$.

Measurement sessions ended on day 6 by the addition of trypsin while monitoring its effect on the impedance of the cellcovered electrode. During trypsin digestion, the time interval between measurements was 5 min until electrodes appeared to be free of neurons.

\section{E. Imaging Technique}

The gold electrode lacked the transparency for direct optical monitoring of the electrode surface. We used the visible area directly surrounding the electrodes to indirectly determine the neuronal coverage of the electrode surface. Percentage of coverage was determined by converting digital color photographs into an 8-bit grayscale photograph using CorelDraw software. The histogram of the grayscale photograph was used for segmentation of the picture into a black-and-white photo. The ratio of the number of black-to-white pixels is the percentage of the electrode area covered by cells. Pictures of the electrode areas were made after every impedance measurement. On each photograph, an area of $200 \mu \mathrm{m}^{2}$ was taken at four different positions. The average percentage of coverage at these four areas was calculated.

\section{RESULTS}

\section{A. Electrodes}

In the first experiment, the optimum electrode size of planar electrodes for neuronal coverage was investigated at frequencies of 5, 10, 100, 500, 1000, 10000 , and $20000 \mathrm{~Hz}$. The sensitivity of these electrodes for cell coverage was calculated as a percentage of the increase in impedance after maximum coverage of the electrodes with neuronal cells. Maximum electrode coverage was accomplished by culturing at a cell density of $1 \times 10^{6}$ cells $/ \mathrm{cm}^{2}$, during six days, before the period that at some parts of the culture aggregates were developing. The development of a neuronal culture during these six days is represented in Figs. 5 and 6. In these figures, we plotted the real and imaginary parts of the impedance together with the change in cell coverage in the electrode area. Directly after cell seeding, a clear rise in the real part of the impedance at a frequency of $10 \mathrm{kHz}$ is seen due to the attachment and spreading of the neuronal cells. After $6 \mathrm{~h}$, the increase flattens, but progresses slowly. This effect on the real impedance is not seen at a frequency of $100 \mathrm{~Hz}$ (see Fig. 5). Fig. 7(a)-(d) shows the impedance loci for all electrode sizes for both noncovered electrodes and electrodes covered with a 6-day-old neuron culture. The highest frequencies show the lowest real and imaginary impedance. As expected, larger electrodes demonstrate lower impedances. The presence of a 6-day-old neuronal culture on top of the electrodes 


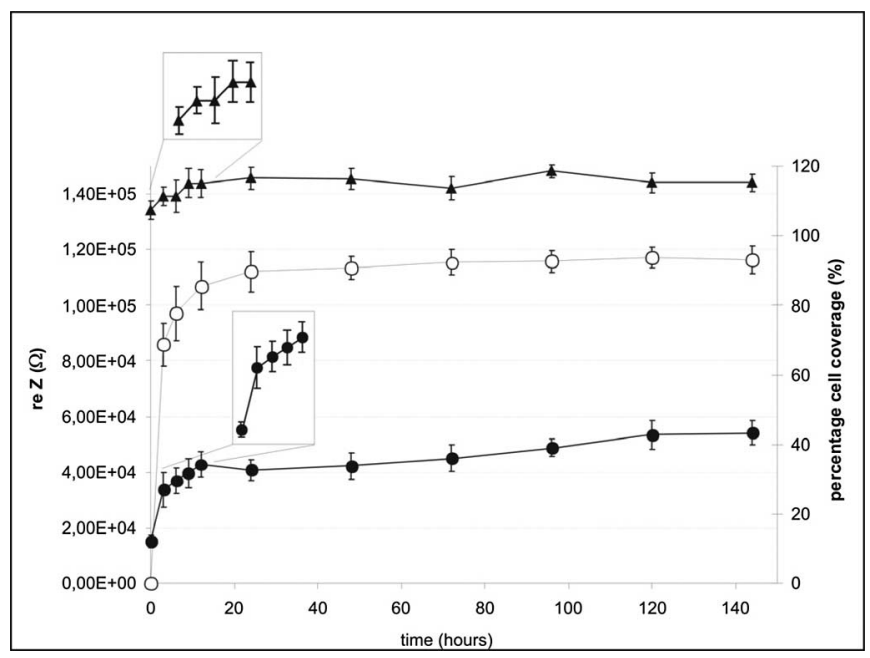

Fig. 5. Real impedance (left vertical scale) during the development of a neuronal cell culture after cell seeding at frequencies of $100 \mathrm{~Hz}(-\boldsymbol{\Delta}-)$ and $10 \mathrm{kHz}\left(\longrightarrow-\right.$ ) (electrode size $7850 \mu \mathrm{m}^{2}$ ). Microscopy: Percentage cell coverage $(-\mathrm{O}-)$ is indicated on the right vertical axis. Inserts: Enlarged version of initial impedance development. $N=5$.

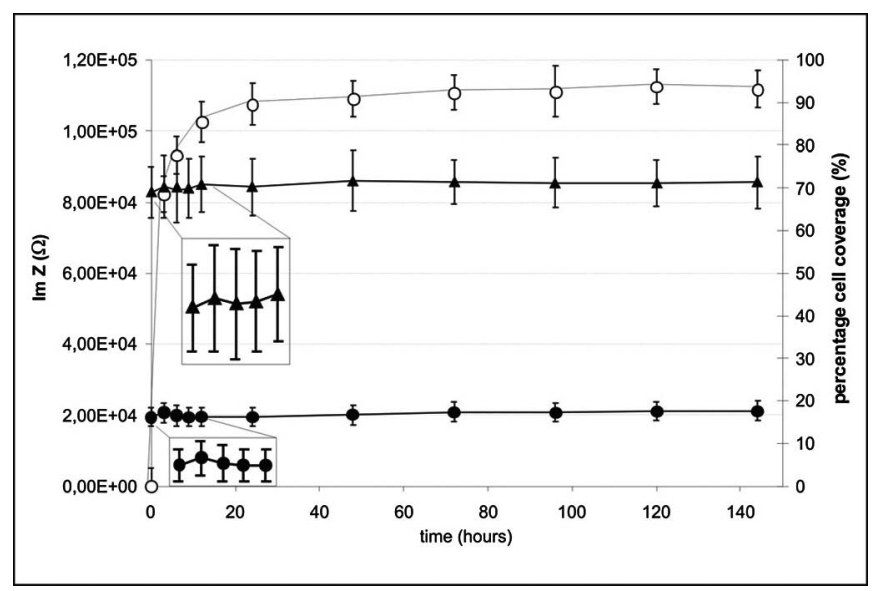

Fig. 6. Imaginary impedance (left vertical scale) during the development of a neuronal cell culture after seeding at frequencies of $100 \mathrm{~Hz}(\boldsymbol{- \Lambda}-)$ and $10 \mathrm{kHz}\left(-\longrightarrow\right.$ ) (electrode size $7850 \mu \mathrm{m}^{2}$ ). Microscopy: Percentage cell coverage (-O-) is indicated on the right vertical axis. Inserts: Enlarged version of initial impedance development. $N=5$.

causes an increase of the real impedance at higher frequencies (horizontal shift to the right).

As can be seen in Fig. 8, the impedance of the applied electrodes at low frequencies show a small rise of impedances at frequencies below $500 \mathrm{~Hz}$. Standard deviations are relatively high.

Strongest effects were obtained using the $7850 \mu \mathrm{m}^{2}$ electrodes at frequencies of 10 and $20 \mathrm{kHz}$. At these frequencies, the cell coverage of electrodes alters the real impedance with more than $250 \%$ (see Fig. 8). In contrast, effects on the imaginary part of the impedance were low at all frequencies, with a maximum change of $14 \%$ at $10 \mathrm{~Hz}\left(1962 \mu \mathrm{m}^{2}\right.$ electrode, data not shown). This makes the imaginary part of the impedance less attractive for future use in electric cell sensing. Therefore, for further monitoring of neuronal development in culture, the

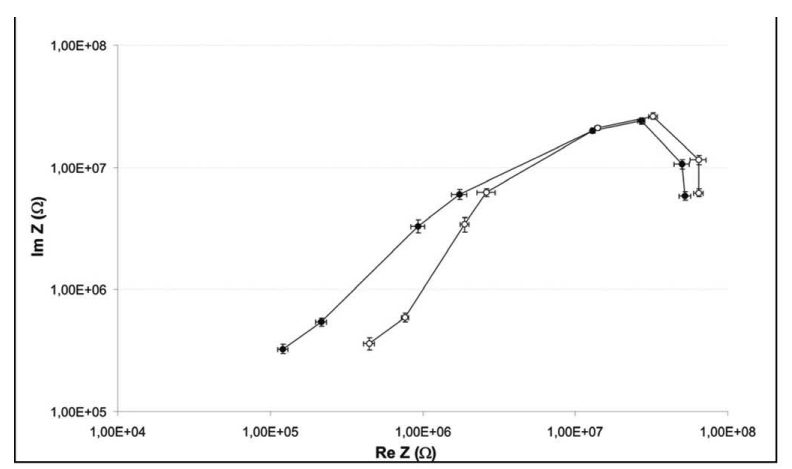

(a)

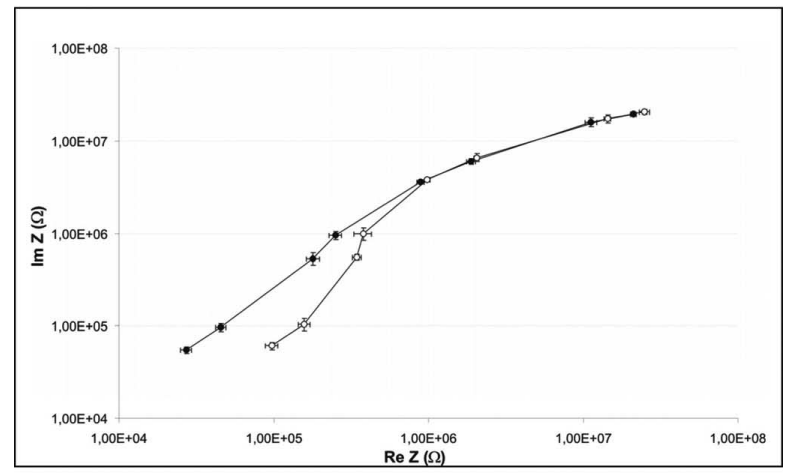

(b)

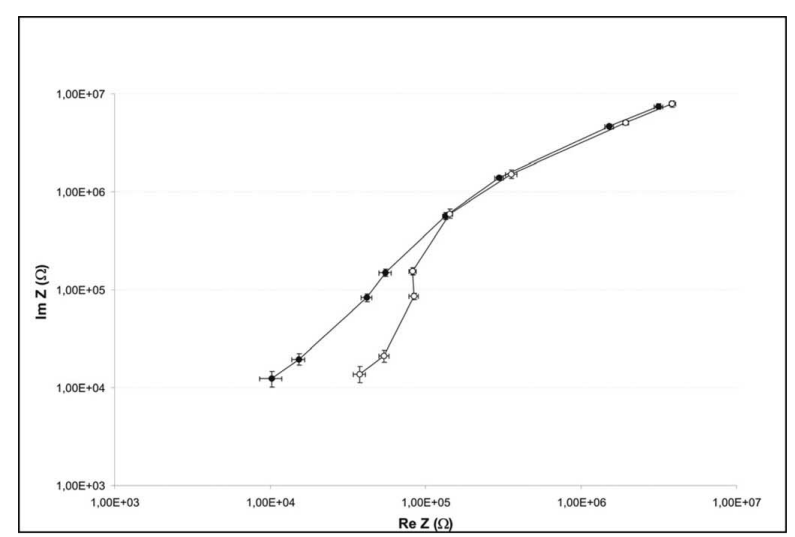

(c)

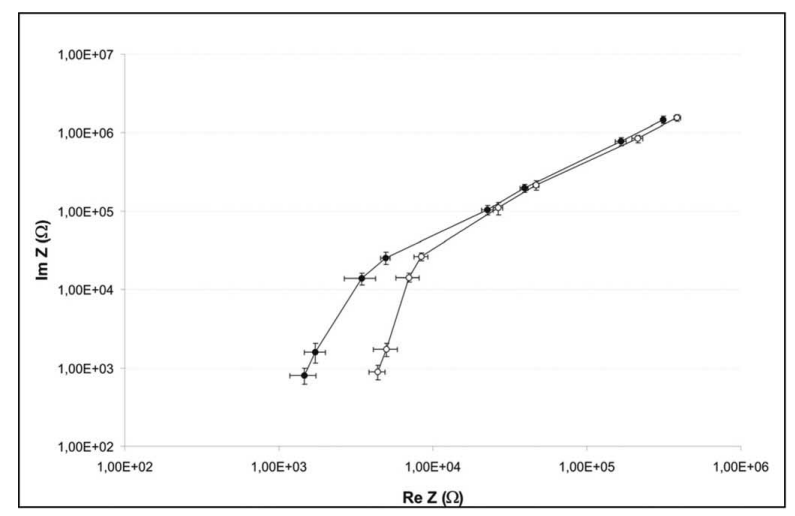

(d)

Fig. 7. (a)-(d) Impedance locus of electrodes with full cell coverage and without cells (-O- and - 10000 , and $20000 \mathrm{~Hz}$ going (from upper right to lower left). Electrodes sizes: (a) $78 \mu \mathrm{m}^{2}$. (b) $1962 \mu \mathrm{m}^{2}$. (c) $850 \mu \mathrm{m}^{2}$. (d) $125600 \mu \mathrm{m}^{2}$. Bars indicate standard deviation. $N=5$. 


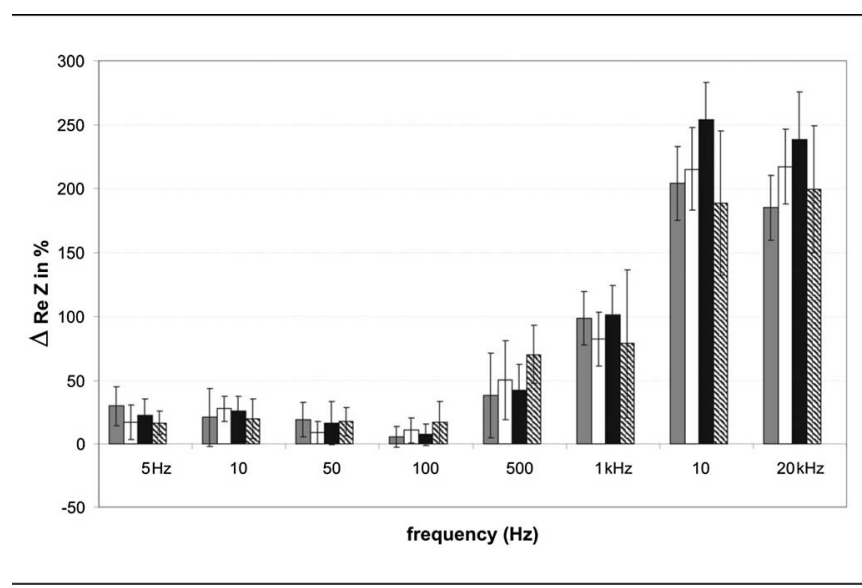

Fig. 8. Percentage of change in real impedance between bare and neuroncovered electrodes of various sizes $\left(78 \mu \mathrm{m}^{2}=\right.$ gray, $1962 \mu \mathrm{m}^{2}=$ white, $7850 \mu \mathrm{m}^{2}=$ black, and $125600 \mu \mathrm{m}^{2}=$ hatched). $N=5$.

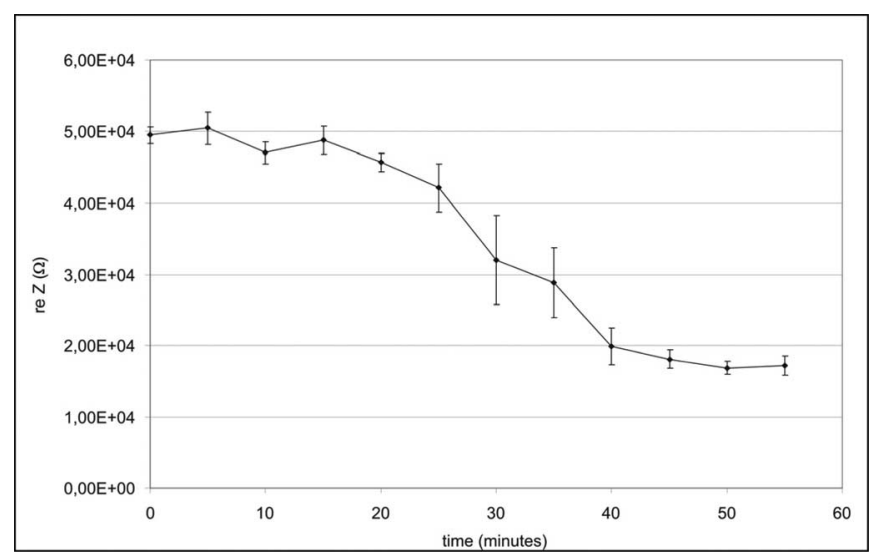

Fig. 9. Real impedance during trypsin digestion of a neuronal cell culture (electrode size $7850 \mu \mathrm{m}^{2}$, frequency $10 \mathrm{kHz}$ ). $N=5$.

$7850 \mu \mathrm{m}^{2}$ electrode was used to record the real impedance at a frequency of $10000 \mathrm{~Hz}$.

After six days, the experiments were finalized by the addition of trypsin, serving as a control to see if the impedance was effected by anything else than culture development. Impedances decreased to the noncovered value in about $40 \mathrm{~min}$ (see Fig. 9).

\section{B. Model Fit}

Impedance loci of electrodes have been simulated by fitting (1) to the measured impedance loci. Fig. 10 represents the measured and fitted loci of both 7850 and $125600 \mu \mathrm{m}^{2}$ electrodes, before and during cell coverage at frequencies of 5, 10, 100, 500, 1000, 10000 , and $20000 \mathrm{~Hz}$. The highest frequencies are plotted in the lower left corner of the graph. As frequency decreases, both real $Z$ and imaginary $Z$ increase. The two leftmost curves are those of the $125600 \mu \mathrm{m}^{2}$ electrodes (most left curve is the uncovered case). The loci of the noncovered and cell covered $7850 \mu \mathrm{m}^{2}$ electrodes represent much higher real and imaginary impedances as expected. Like in Fig. 7, the presence of a 6-dayold neuronal culture on top of the electrodes causes an increase of the real impedance at higher frequencies for both electrode

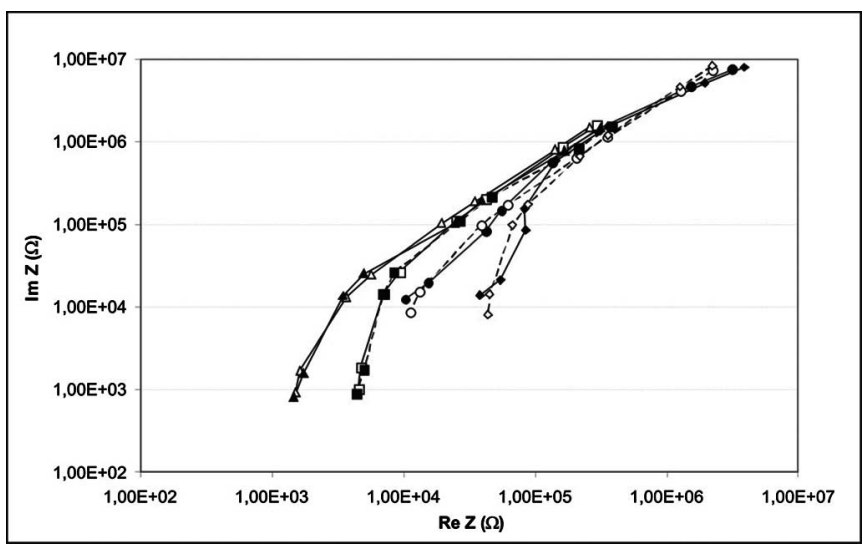

Fig. 10. Example of two impedance loci $\left(7850 \mu \mathrm{m}^{2}\right.$ and $125600 \mu \mathrm{m}^{2}$ electrodes) before and after neuron coverage with the modeled loci fitted to the measured data. $-\bullet-7850 \mu \mathrm{m}^{2}$ noncovered measured, $-\mathrm{O}-=$ $7850 \mu \mathrm{m}^{2}$ noncovered fit; $-\longrightarrow=7850 \mu \mathrm{m}^{2}$ covered measured, $-\diamond-=$ $7850 \mu \mathrm{m}^{2}$ covered fit; $-\boldsymbol{\Delta}-=125600 \mu \mathrm{m}^{2}$ noncovered measured, $-\Delta-=125600 \mu \mathrm{m}^{2}$ noncovered fit $-\square-=125600 \mu \mathrm{m}^{2}$ covered measured, $-\square-=125600 \mu \mathrm{m}^{2}$ covered fit.

TABLE I

Model Parameters FitTed to the EXPERIMENTAL IMPEDANCE SPECTRA OF NONCOVERED (BARE) AND COVERED ELECTRODES

\begin{tabular}{|c|c|c|c|}
\hline Electrode size $\mu \mathrm{m}^{2}$ & $\mathrm{R}_{\text {spread }}[\mathrm{Ohm}]$ & $\mathrm{m}$ & $\mathrm{K}$ \\
\hline 78 bare & 0.00 & 0.76 & $2.60 * 10^{9}$ \\
\hline 78 covered & $3.04 * 10^{5}$ & 0.72 & $2.24 * 10^{9}$ \\
\hline 1962 bare & $1.19 * 10^{3}$ & 0.74 & $3.86 * 10^{8}$ \\
\hline 1962 covered & $7.92 * 10^{4}$ & 0.73 & $3.98 * 10^{8}$ \\
\hline 7850 bare & $8.46 * 10^{3}$ & 0.81 & $1.24 * 10^{8}$ \\
\hline 7850 covered & $4.13 * 10^{4}$ & 0.83 & $1.51 * 10^{8}$ \\
\hline 125600 bare & $1.34 * 10^{3}$ & 0.89 & $3.23 * 10^{7}$ \\
\hline 125600 covered & $4.36 * 10^{3}$ & 0.88 & $3.34 * 10^{7}$ \\
\hline
\end{tabular}

coverage. The spreading resistance, however, increases drastically after coverage.

sizes. This increase is represented by the horizontal shift of the impedance locus in the lower left corner of the loci.

The impedance loci could be fitted by a multivariable leastsquare-fit selection procedure of values for the parameters $K, m$, and $R_{\text {spread. }}$. The values are listed in Table I (noncovered electrodes and neuron-covered electrodes). The tables and plotted impedance loci show that neuron coverage mainly affects the real-valued $R_{\text {spread }}$.

\section{Calculation of Change in Impedance Based on Microscopy}

In Fig. 11, the increase of the real impedance $\Delta \operatorname{Re} Z$ (equal to $R_{\text {spread }}$, filled circles) of the $7850 \mu \mathrm{m}^{2}$ electrode during culture development is plotted, together with the percentage of electrode coverage, as determined from microscopy and image analysis (open-circle symbols). The experimental $\Delta \operatorname{Re} Z$ data (filled circles) in Fig. 11 are derived from Fig. 5 by subtracting the real impedance of the uncovered electrode, thereby obtaining the change in real impedance during culture development. (In contrast to the real impedance, there is nearly no change in imaginary impedance at high frequency between uncovered and fully covered electrode condition.) On the other hand, the change in real impedance can be derived from the optical 


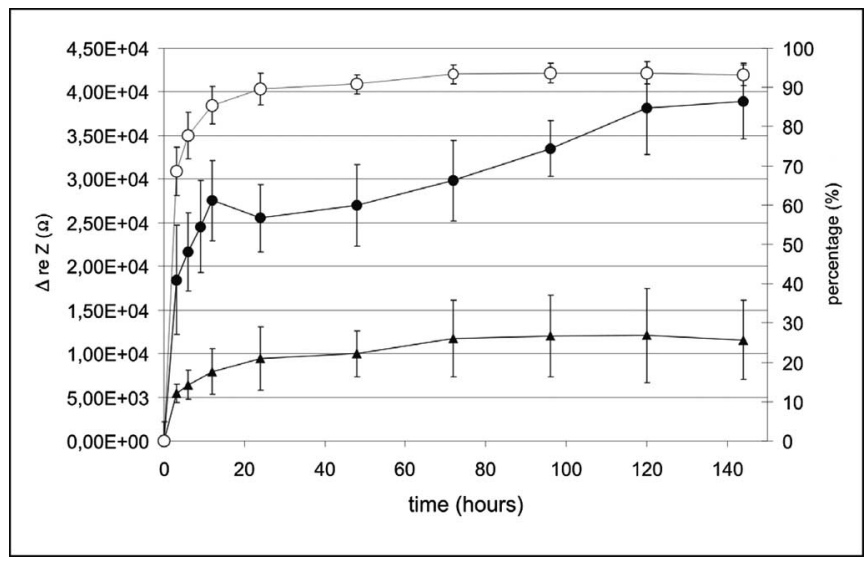

Fig. 11. Measured change $\Delta \operatorname{Re} Z$ during the development of a neuronal cell culture after seeding at $10 \mathrm{kHz}(-\bullet-)$ on the left $y$-axis. Change $\Delta \operatorname{ReZ}$ calculated from the cell coverage, determined by image analysis $(-\mathbf{\Delta}-)$ on the left axis. Percentage cell coverage obtained by microscopy, right $y$-axis $\left(\right.$ (一一). $N=5$. Electrode size $=7850 \mu \mathrm{m}^{2}$.

coverage data using the following equation:

$$
\Delta \operatorname{Re} Z=R_{\text {spread }}=\frac{\sqrt{2}}{2 \pi \sigma r_{e}} \approx \frac{1}{4.44 \sigma r_{e}} .
$$

As conductivity, we used $1.65 \mathrm{~S} / \mathrm{m}$. Radius $r_{e}$ is the equivalent radius of the noncovered electrode surface and can be calculated from the optically determined electrode coverage $A_{e}$

$$
r_{e}=\sqrt{\left(A_{e} / \pi\right)} .
$$

This "optically inferred" change in impedance $R_{\text {spread }}$ is also plotted in Fig. 11 (triangle symbols).

The difference between the two curves (measured versus optically inferred one) is striking. The absolute values differ considerably, but also the detailed course over time, the IS-measured curve showing the most detail.

\section{DISCUSSION}

IS of cellular systems has shown to be effective in monitoring cell spreading and adhesion. Change in impedance is mainly caused by the progressive "insulating" properties of cells. So far IS has been applied on cell types proliferating in 2-D monolayers with tight intracellular spaces, like epithelial and endothelial cells. However, neurons do not proliferate and cell junctions are far less tight. Electrodes were applied in neuronal cell sensing to study the applicability of IS in the monitoring of neuronal cell cultures. Four sizes of electrodes were compared. For all electrodes, a clear effect of neuronal cell covering on the electrode impedance has been demonstrated; the maximal effect was seen for an electrode with size 7850. Increase of real impedance after cell coverage was $254 \%$ at $10 \mathrm{kHz}$. Wegener et al. [7] indicated a frequency of $40 \mathrm{kHz}$ as measured optimum for cell sensing (but for epithelial cells, electrode surface $50000 \mu \mathrm{m}^{2}$ ).

Neuronal cultures that are kept longer than six days in vitro have a denser morphology compared to the final state of the cultures measured in this study. Aggregation of neurons in such cultures, however, causes nonhomogeneous covering of electrodes, and is therefore, less interesting for this study.

We also tested interdigitated electrodes (results not shown). They were reported as more applicable for IS [18] because of better sensitivity and reproducibility. The results obtained in this study do not support this conclusion for neuronal cultures. Possible reason is the larger intercellular space in neuronal cultures, resulting in a lower $R_{\text {spread }}$, outshining the capacitive effect. After completely removing the neuronal cultures by trypsin digestion, electrode impedance turned back to the initial impedance of the empty electrodes.

The monitoring of neuronal cultures in development is presented in Fig. 5. At $10 \mathrm{kHz}$, over $50 \%$ of the increase in real impedance is caused by the attachment and spreading of neurons in the first $3 \mathrm{~h}$. The percentage of electrode coverage (optical) demonstrates a similar increasing trend as the real impedance during the first $24 \mathrm{~h}$. No further increase in neuronal coverage of the electrode is seen after $24 \mathrm{~h}$. The real impedance, however, increases further after $24 \mathrm{~h}$. This indicates that IS can detect changes in neuronal cultures that are undetectable using normal microscopy.

The impedance inferred from the optically determined cell coverage is plotted in Fig. 11 (triangles). This calculated impedance is considerably less than the measured impedance (closed circles) and shows less detail. This implies that microscopy reveals too much open space (maximum coverage in Fig. 11 is $93 \%$, so $7 \%$ open space). There may be several reasons why microscopy gives less accurate results. Only an on-top view of a culture can be achieved, making it difficult to obtain data from the cell-substrate area. Also, at high cell densities, neurons are at close proximity. At these small distances, the halo effect caused by phase-contrast microscopy [21] obscures much of the clear vision on the soma's distal regions (which consist of very thin lamellae) and cellular processes. The halo effect makes it also hard to distinguish somas from axonal outgrowth, cell debris, and noncovered substrate. In Fig. 11, at a maximum cell coverage of $93 \%$, the extent of cell-cell contacts seems to be poor. However, when we detached the tissue from the substrate, we observed a floating "monopiece" sheet of cells, indicating a much better than poor extent of cell-cell contact in dense neuronal cultures. The conclusion can be drawn that IS shows more details and is more accurate about coverage. It is also a relatively simple technique, yet yielding quantitative data on culture development.

\section{REFERENCES}

[1] C. F. Crouche, H. W. Fowler, and R. E. Spier, "The adhesion of animal cells to surfaces: The measurement of critical surface shear stress permitting attachment or causing detachment," J. Chem. Tech. Biotechnol., AE, vol. 35, pp. 273-281, 1985.

[2] L. S. Chanavajjala, A. Eidsath, and W. Saxinger, "A simple method for measurement of cell-substrate attachment forces: Application to HIV-1 Tat," J. Cell Sci., vol. 110, pp. 249-256, 1997.

[3] V. Hedin, B. A. Bottger, J. Luthman, S. Johansson, and J. Thyberg, "A substrate of the cell-attachment sequence of fibronectin is a sufficient to promote transition of arterial smooth muscle cells from a contractile to a synthetic phenotype," Dev. Biol., vol. 133, pp. 489-501, 1989.

[4] G. M. Edelman, "Modulation of cell adhesion during induction, histogenesis, and perinatal development of the nervous system," Апnи. Rev. Neurosci., vol. 7, pp. 339-377, 1984. 
[5] L. Dillner, K. Dickerson, M. Manthrope, E. Ruoslahti, and E. Engvall, "The neuritepromoting domain of human laminin promotes attachment and induces characteristic morphology in non-neuronal cells," Exp. Cell Res., vol. 177, pp. 186-198, 1988.

[6] I. Giaever and C. R. Keese, "Micromotion of mammalian cells measured electrically,” Proc. Nat. Acad. Sci. USA, vol. 88, pp. 7896-7900, 1991.

[7] J. Wegener, I. Giaever, and C. R. Keese, "Electric cell-substrate impedance sensing (ECIS) as a noninvasive means to monitor the kinetics of cell spreading to artificial surfaces," Exp. Cell Res., vol. 259, pp. 158-166, 2000.

[8] Y. Y. Duan, G. M. Clark, and R. S. C. Cowan, “A study of intra-cochlear electrodes and tissue interface by electrochemical impedance methods in vivo," Biomaterials, vol. 25, pp. 3813-3828, 2004.

[9] J. R. Buitenweg, W. L. C. Rutten, W. P. A. Willems, and J. W. van Nieuwkasteele, "Measurement of sealing resistance of cell-electrode interfaces in neuronal cultures using impedance spectroscopy," Med. Biol. Eng. Comput., vol. 36, pp. 630-637, 1998.

[10] J. R. Buitenweg, W. L. C. Rutten, and E. Marani, "Geometry based finiteelement modeling of the electrical contact between a culture neuron and a microelectrode," IEEE Trans. Biomed. Eng., vol. 50, no. 4, pp. 501-509, Apr. 2003.

[11] C. Tiruppathi, A. B. Malik, P. J. D. Vecchio, C. R. Keese, and I. Giaever, "Electrical method for detection of endothelial cell shape change in real time: Assessment of endothelial barrier function," Proc. Nat. Acad. Sci. USA, vol. 89, pp. 7919-7923, 1992.

[12] L. Reddy, H. S. Wang, C. R. Keese, I. Giaever, and T. J. Smith, "Assessment of rapid morphology changes associated with cAMP levels in human orbital fibroblasts," Exp. Cell Res., vol. 245, pp. 360-367, 1998.

[13] C. Xiao, B. Lachance, G. Sunahara, and J. Luong, "Assessment of cytotoxicity using electric cell-substrate impedance sensing: Concentration and time response function approach," Anal. Chem., vol. 74, pp. 5748-5753, 2002
[14] M. McCoy and E. Wang, "Use of electrical cell-substrate impedance sensing as a tool for quantifying cytophatic effect in influenza A virus infected MDCK cells in real-time," J. Virol. Methods, vol. 130, pp. 157161, 2005.

[15] C. M. Lo, C. R. Keese, and I. Giaever, "pH changes in pulsed $\mathrm{CO}_{2}$ incubators cause periodic changes in cell morphology," Exp. Cell Res. vol. 213, pp. 391-397, 1994.

[16] E. Bieberich and A. Guiseppi-Elie, "Neuronal differentiation and synapse formation of PC12 and embryonic stem cells on interdigitated microelectrode arrays: Contact structures for neuron-to-electrode signal transmission (NEST)," Biosens. Bioelectron., vol. 19, pp. 923-931, 2004.

[17] K. V. Sharma, C. Koenigsberger, S. Brimijoin, and J. W. Bigbee, "Direct evidence for an adhesive function in the noncholinergic role of acetylcholinesterase in neurite outgrowth," J. Neurosci. Res., vol. 63, pp. 165$175,2001$.

[18] R. Ehret, W. Baumann, M. Brischwein, A. Schwinde, and B. Wolf, "Online control of cellular adhesion with impedance measurements using interdigitated electrode structures," Med. Biol. Eng. Comput., vol. 36, pp. 365-370, 1998.

[19] R. W. de Boer and A. van Oosterom, "Electrical properties of platinum electrodes: Impedance measurements and time-domain analysis," Med. Biol. Eng. Comput., vol. 16, pp. 1-10, 1978.

[20] H. J. Romijn, F. V. Huizen, and P. S. Wolters, "Towards an improved serum free, chemically defined medium for long term culturing of cerebral cortex tissue," Neurosci. Biobehav. Rev., vol. 8, pp. 301-344, 1984.

[21] F. Zernike, "Phase contrast, a new method for the microscopic observation of transparent objects," Physica, vol. 10, pp. 974-986, 1942.

Authors' photographs and biographies not available at the time of publication. 